\title{
STUDY OF FRONTAL AIR SINUS OPENING IN HIATUS SEMILUNARIS
} OF NASAL CAVITY

\section{Shashikant B. Mane *1, Madhav P.Kanse 2, Hema S. Mohite ${ }^{3}$, Shila D. Kadam 4.}

${ }^{{ }^{1}}$ Professor, Department of Anatomy, Krishna Institute of Medical Sciences University, Karad, India.

${ }^{2}$ Tutor, Department of Anatomy, Krishna Institute of Medical Sciences University, Karad, India.

${ }^{3}$ P.G student, Department of Anatomy, Krishna Institute of Medical Sciences University, Karad, India.

${ }^{4}$ P.G student, Department of Anatomy, Krishna Institute of Medical Sciences University, Karad, India.

\section{ABSTRACT}

Background: Frontal air sinus opens in Hiatus semilunaris of middle meatus of Nasal cavity. Nowadays plenty of endoscopic surgeries are happening at Middle meatus; so there is need to explore more about detail anatomy of opening of sinuses. So Present study was undertaken to note the exact site of opening of Frontal air sinus in Hiatus semilunaris of Nasal cavity.

Context and Purpose of study: Study was conducted on 50 specimens. Out of that 27 were from Right side \& 23 were from Left side. The specimens were the sagittal sections of adult cadavers in the department of Anatomy, Krishna Institute of Medical sciences University, Karad. The parameters measured were, Distance of Frontal air sinus opening from Anterior end of Hiatus semilunaris (nasal bone). Distance of Frontal air sinus opening from Posterior end of Hiatus semilunaris(Inferior surface of Body of Spenoid bone). Diameter of Frontal air sinus opening. Shape of Frontal air sinus opening. All these measurements were taken by Sliding Vernier Caliper of $30 \mathrm{~cm}$ length \& 0.001 accuracy.

Results: The mean Distance of Frontal air sinus opening from Anterior end of Hiatus semilunaris (nasal bone) was- $1.63 \mathrm{cms}$ on Left side \& $1.52 \mathrm{cms}$ on Right side. The mean Distance of Frontal air sinus opening from Posterior end of Hiatus semilunaris(Inferior surface of Body of Spenoid bone) was- $4.26 \mathrm{cms}$ on Left side \& $4.17 \mathrm{cms}$ on Right side. The mean Diameter of Frontal air sinus opening $-0.19 \mathrm{cms}$ on Left side $\& 0.18 \mathrm{cms}$ on Right side. The shape of Frontal sinus opening is mainly Circular.

Conclusion and Summary: Knowledge of the anatomy of the Frontal air sinus opening is basically helpful for the Anatomists, to know where exactly is the site of the opening of Frontal air sinus in the middle meatus of nasal cavity; And secondarily it might be helpful to ENT surgeons during the performance of endonasal cystorhinostomies.

KEY WORDS: Frontal air sinus, Middle meatus of Nose, Hiatus semilunaris, Nasal cavity, Frontal air sinus opening.

Address for Correspondence: Dr. Shashikant B. Mane, Professor, Department of Anatomy, Krishna Institute of Medical Sciences University, Karad-415110, Dist. Satara, State- Maharashtra, India. Mobile-9822831039 E-Mail: kantmane@gmail.com

Quick Response code

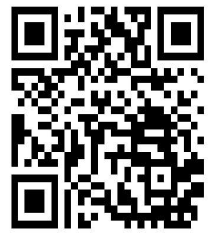

DOI: $10.16965 /$ ijar.2017.481
Journal Information

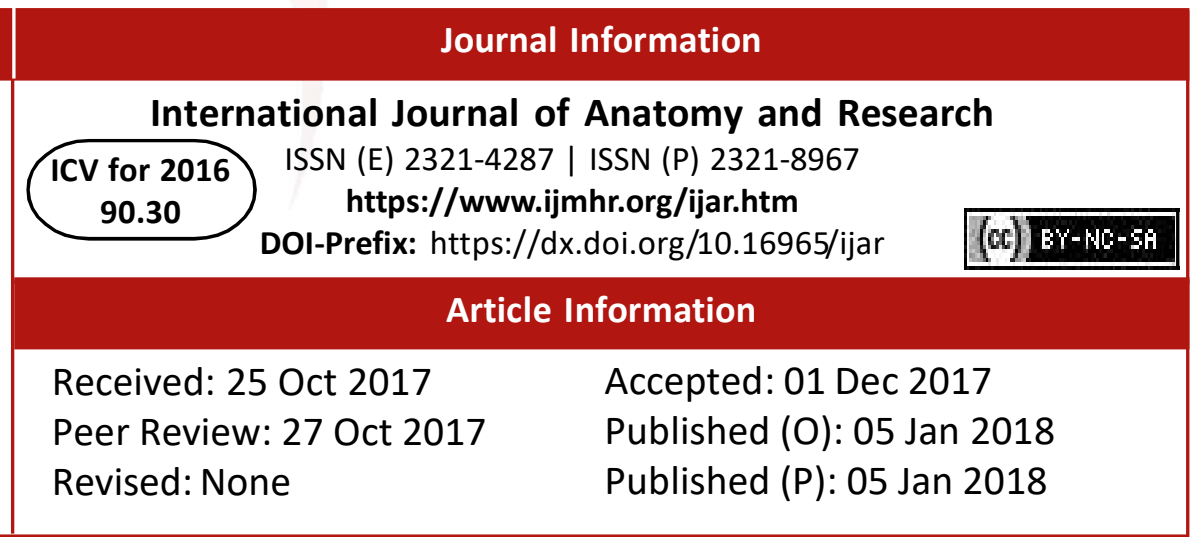




\section{INTRODUCTION}

Frontal air sinus is one of the Paranasal air sinuses. Paranasal air sinuses drain into the Lateral wall of the Nasal cavity. Frontal air sinus drains by frontonasal duct which opens into the anterior end of the middle meatus of the Nasal cavity [1].

Normal drainage of the paranasal sinuses depends on effective mucociliary clearance; this is dependant on the condition of the sinus ostia [2]. The two of the largest sinuses, the frontal and maxillary, communicate with the middle meatus via narrow and delicate prechambers [3].

It is generally held that the frontal sinus commences to develop at the end of the first or the beginning of the second year of life, as an upward expansion of the ethmoid cell labyrinth, Together, the frontal sinus and the superior compartment of the Frontal Sinus Drainage Pathway resemble an Erlenmeyer flask with the neck of the flask representing the frontal ostimum. Anatomical variation of the lateral nasal wall, including the pathway from the frontal, ethmoidal, and maxillary sinuses may affect the communication between the paranasal sinuses and the nasal cavity. The middle meatus and hiatus semilunaris are areas where variations can occur which predispose patients to recurring sinusitis.

When surfaces become more closely apposed due to mucosal swelling, the ciliary action is immobilized. This impairs the ventilation and drainage of larger sinuses, result in mucus stasis, predispose to further infection and establish a vicious cycle, causing chronic sinusitis. The key region for these changes is that part of the lateral nasal wall that encloses the sinus ostia and their adjacent mucosa and prechambers [4].

There is considerable anatomical variation in this area that may interfere with normal nasal function and predispose to recurrent or chronic sinusitis [4]. Because of these reasons current study of frontal air sinus opening is undertaken.

Lateral wall of the Nasal cavity (Photograph-1) shows Hiatus semilunaris below the Middle nasal choncha. Frontal air sinus opens into the Hiatus semilunaris.
Fig. 1: Lateral wall of the nasal cavity.

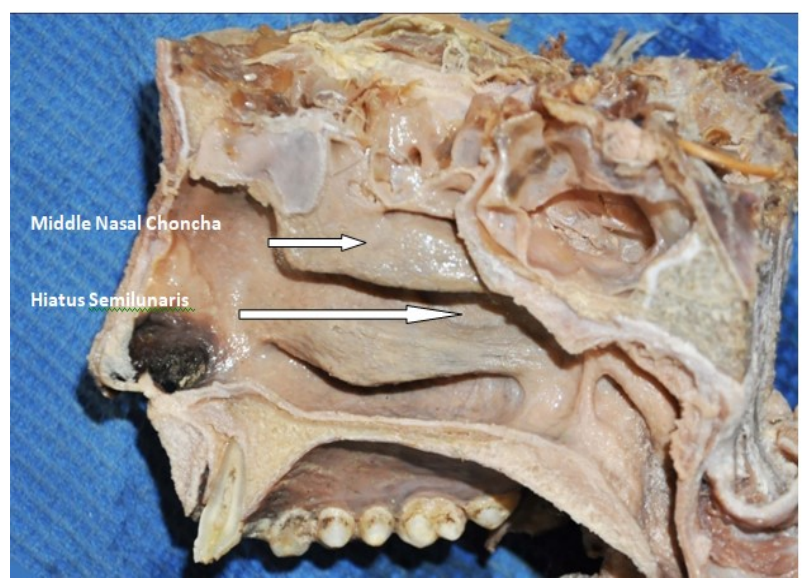

\section{MATERIALS AND METHODS}

This study was carried out on the cadaveric specimens in Krishna institute of medical sciences, Karad, Maharashtra, India.

Total 50(fifty) specimens were studied. Out of that, 23(twenty three) were from Left side, and 27(twenty seven) were from Right side. Formalin preserved cadaveric specimens were taken. Then they were first washed. Then by using Dissection instruments, Lateral wall of the Nasal cavity was nicely exposed. Middle nasal concha is properly dissected, so as to expose the Hiatus semilunaris. Then opening of the Frontal air sinus was noted. The distance of Frontal air sinus opening from Anterior end of Hiatus Semilunaris was measured by using Sliding Vernier Caliper. The distance of Frontal air sinus opening from Posterior end of Hiatus Semilunaris was also measured. Then Diameter of Frontal air sinus opening was measured. Shape of the Frontal air sinus was noted.

Fig. 2: Opening of the Frontal air sinus.

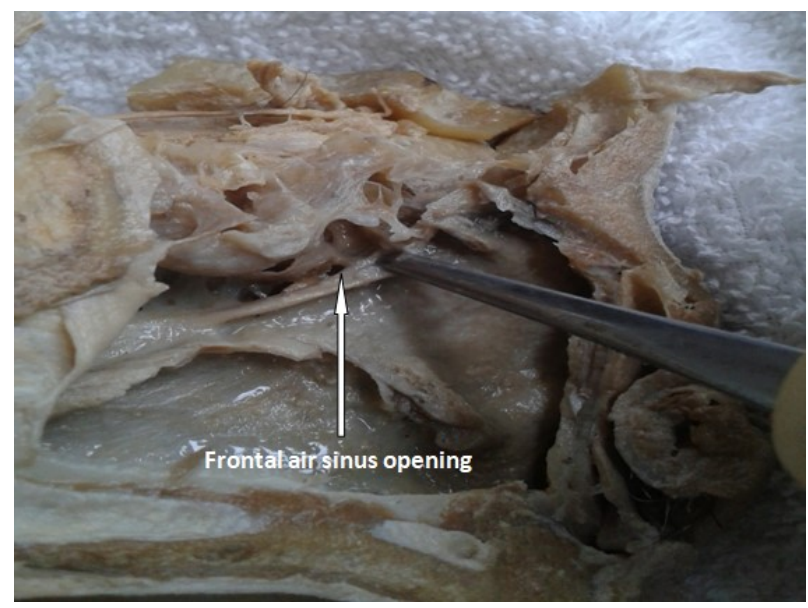

After dissection of middle nasal choncha , Hiatus semilunaris is nicely exposed. Openings of 
the paranasal air sinuses are seen. Photograph2 shows exact opening of the Frontal air sinus. Opening of the Frontal air sinus is shown by the tip of the arrow.

Statistical analysis: Quantitative data was summarized into maximum, minimum, mean and Standard Deviation; while Qualitative data was summarized into number \& percentages. Comparison of quantitative data was done by applying unpaired ' $\mathrm{t}$ ' test while chi-square test was used for qualitative data comparison. Correlation coefficient was determined by using Pearson's correlation method. Difference and Correlation was said to be significant if $p$ was less than 0.05 .

\section{OBSERVATIONS AND RESULTS}

The various parameters of Distance of Frontal air sinus opening from Anterior end of Hiatus Semilunaris are shown in Table-1. Distance of Frontal air sinus opening from Anterior end of Hiatus Semilunaris hasn't shown any significant difference as comparision of sides are considered (' $t$ 'value- 1.118 , ' $p$ 'value- 0.2692 ).

Table 1: Distance of Frontal air sinus opening from Anterior end of Hiatus Semilunaris $(\mathrm{cm})$.

\begin{tabular}{|c|c|c|}
\hline & Right side & Left side \\
\hline Maximum & 2.42 & 3.37 \\
\hline Minimum & 0.72 & 1.15 \\
\hline Mean & 1.52 & 1.63 \\
\hline $\begin{array}{c}\text { Standard } \\
\text { deviation }\end{array}$ & 0.4 & 0.49 \\
\hline
\end{tabular}

Parameters of Distance of Frontal air sinus opening fromPosterior end of Hiatus Semilunaris are shown in Table-2. Sidewise difference in the case of Distance of Frontal air sinus opening from Posterior end of Hiatus Semilunaris is also not significant (' $t$ 'value- 0.2447 , ' $p$ 'value0.8078).

Table 2: Distance of Frontal air sinus opening from Posterior end of Hiatus Semilunaris $(\mathrm{cm})$.

\begin{tabular}{|c|c|c|}
\hline & Right side & Left side \\
\hline Maximum & 6.38 & 6.76 \\
\hline Minimum & 2.05 & 2.33 \\
\hline Mean & 4.17 & 4.26 \\
\hline $\begin{array}{c}\text { Standard } \\
\text { deviation }\end{array}$ & 1.33 & 1.38 \\
\hline
\end{tabular}

Diameter of opening of the Frontal air sinus in Hiatus semilunaris on Right \& Left side shows following results (Table-3)
Table 3: Diameter of opening of the Frontal air sinus in Hiatus semilunaris on Right \& Left side $(\mathrm{cm})$.

\begin{tabular}{|c|c|c|}
\hline & Right side & Left side \\
\hline Maximum & 0.39 & 0.31 \\
\hline Minimum & 0.05 & 0.11 \\
\hline Mean & 0.18 & 0.19 \\
\hline $\begin{array}{l}\text { Standard } \\
\text { deviation }\end{array}$ & 0.08 & 0.06 \\
\hline
\end{tabular}

Diameter of opening of the Frontal air sinus in Hiatus semilunaris on Right \& Left side doesn't show stastistically significant difference ('t'value- 0.4741, 'p'value- 0.6376 ).

Shape of the opening of the Frontal air sinus in Hiatus semilunaris was mainly Circular on the Right as well as on the Left side (Table-4).

Table 4: Shape of the opening of the Frontal air sinus in Hiatus semilunaris.

\begin{tabular}{|c|c|c|c|c|c|c|}
\hline & \multicolumn{3}{|c|}{ Right side } & \multicolumn{3}{c|}{ Left side } \\
\hline Type & No & Total & $\%$ & No & Total & $\%$ \\
\hline Oval & 6 & 27 & 22.2 & 6 & 23 & 26.09 \\
\hline Circular & 21 & 27 & 77.8 & 17 & 23 & 72.91 \\
\hline
\end{tabular}

\section{DISCUSSION}

Average Diameter of the opening of Frontal air sinus into the Hiatus semilunaris, according to our study is: on Right side is $0.18 \mathrm{~cm} \&$ on the Left side is $0.19 \mathrm{~cm}$. As per the study of Landsberg $\mathrm{R}$ et al [5], Average anteroposterior diameter of the opening of Frontal air sinus into the Hiatus semilunaris is $7.2 \mathrm{~mm}$ and transverse diameter is $8.9 \mathrm{~mm}$.

Our study shows Shape of the opening of the Frontal air sinus into the Hiatus semilunaris is mainly Circular, $77.8 \%$ on the Right side and $72.9 \%$ on the Left side.

According to our study the Frontal air sinus opens into the anterior part of Hiatus semilunaris. Gray's anatomy mentions opening of the Frontal air sinus into the upper and anterior part of the Hiatus semilunaris [15]. Our study correlates with that. According to article in AJNR, left side shows multiple openings of the frontal sinuses [8]. According to D'Souza et al [10], sinus opens into the osteomeatal complex. Osteomeatal complex is the term used for a group of anatomical structures that contribute to the final common drainage pathway of Maxillary, Anterior Ethmoidal and Frontal sinuse [12].Frontal sinus open into the hiatus semilunaris in the middle meatus [16]. 
Frontal sinus opens in the infundibulum which is at the anterosuperior end of the hiatus semilunaris [17]. The frontal sinus ostium opens inferiorly into the frontal sinus recess [14]. One perticular type of frontal sinus cell is a single isolated cell that exists completely within the frontal sinus and has no connection to the frontal recess [18]. Where the sinus frontalis has two nasofrontal ducts, the drainage is of course partly into the middle meaus and partly into the infundibulum ethmoidale [13]. As far as our study is concerned, in all cases, Frontal air sinus opens by one way only, and that into the anterior part of the Hiatus semilunaris.

\section{CONCLUSION}

Frontal air sinus opens into the Anterior part of the Hiatus semilunaris. Average distance of Frontal air sinus opening from Anterior end of Hiatus Semilunaris is $1.52 \mathrm{~cm}$ on the Right side $\& 1.63 \mathrm{~cm}$ on the Left side. Average distance of Frontal air sinus opening from Posterior end of Hiatus Semilunaris is $4.17 \mathrm{~cm}$ on the Right side $\& 4.26 \mathrm{~cm}$ on the Left side. Average diameter of Frontal air sinus opening on Right side is 0.18 $\mathrm{cm}$ \& on the Left side is $0.19 \mathrm{~cm}$. Shape of the opening of the Frontal air sinus into the Hiatus semilunaris, is mainly Circular. The anatomical variants of the paranasal sinuses are not incidental, being found in a large number of patients and may be a predisposing factor in the onset and recurrence of sinuses inflammation [6].

The endoscopic bidimensional vision offered by the endoscope during endoscopic sinus surgery involves difficulty in visualizing surgical field depth which makes it difficult to learn this surgical technique and makes it necessary for the endoscopic surgeon to mentally create a threedimensional (3D) picture of the paranasal sinuses anatomy, In particular, Frontal recess surgery [7].

Surgery on the frontal recess and frontal sinus remains a challenge for endoscopic sinus surgeons. An increased understanding of the anatomy of this region should improve the surgeon's surgical confidence and ability to remove all the obstructing cells from the frontal sinus ostium [9].

\section{ACKNOWLEDGEMENTS}

The great help we got from the Department of
Preventive and Social Medicine for which we record our greatfulness.

\section{Conflicts of Interests: None}

\section{REFERENCES}

[1]. Williams \& Warwick, Gray's anatomy, $36^{\text {th }}$ Edition, New York, Churchill Livingstone; 1980: 1142.

[2]. Vijay Bajaj et al, Prevelance of Anatomical variations of lateral wall of Nose in chronic sinusitis, J of Evolution of Med and Dent Sci. 2015;4(32):5492.

[3]. Hilding A, Physiology of drainage of nasal mucous: experimental work on accessory sinuses, Am J of Physiol, 1932; 100:664

[4]. Zinreich SJ et al, CT of nasal cavity, paranasal sinuses: An evaluation of anatomy in endoscopic sinus surgery, Clear Images 1988; 2:2-10.

[5]. Landsberg $R$ et al, A computer-assisted anatomical study of the nasofrontal region, Laryngoscope, 2001 Dec; 111(12):2125-30.

[6]. Raluca R et al, Assessing the prevalence of paranasal sinuses Anatomical variants in patients with sinusitis using cone beam computer tomography, Clujul Medical 2016;89 (3):423-429.

[7]. The frontal sinus drainage pathway and related structures, https://www.researchgate.net/publication/9887858:23/24.

[8]. Frontal sinus drainage pathway, The frontal sinus drainage pathway and related structures, AJNR 2003;17(24).

[9]. Peter J., Surgery of the frontal recess and frontal sinus, July 2005, https://www.researchgate.net/publication/7736631,5/12

[10]. D'Souza et al, Anatomical study of the middle meatus with emphasis to the maxillary ostium and their clinical relevance, International Journal of Health Sciences \& Research, 2015;4(2):35-39. ISSN 2249-9571

[11]. The sinus maxillaries and its relations in the embryo, child, and adult man - Embryology, https:// embryology.med.unsw.edu.au/embryology/ index.php, 3/15

[12]. Singhal $\mathrm{M}$ et al, Maxillary sinus ostium- Morphology and its clinical relevance, Cibtech J of Surg 2013;2(3):26-29.

[13]. Embryology,The sinus maxillaries and its relations in the embryo, child, and adult man - https:// embryology.med.unsw.edu.au/embryology/ index.php, 12/15

[14]. Ameet singh, Paranasal sinus Anatomy, Paranasal sinus/emedicine.medscape.com

[15]. Williams \& Warwick, Gray's anatomy, 36 th Edition, New York, Churchill Livingstone; 1980: 314

[16]. https://en.m.wikipedia.org

[17]. The nose and paranasal sinuses, http://www.ucd.ie/ vetanat/ga-subjecd/head \&neck/hn8.html

[18]. David L et al, The frontal sinus drainage pathway and related structures, https://www.researchgate .net / publication/9887858:3/24 
[19]. Kelly D et al, Anatomic description of the middle meatus and classification of the hiatus semilunaris into five types based upon morphological characteristics, Clinical Anatomy 2014;27(2):176-181.

[20]. Langille $\mathrm{M}$ et al, Frontal sinus cells: identification, prevalence and association with frontal sinus mucosal thickening, Am J Rhinol Allergy.2012;26(3): e107-10.

How to cite this article:

Shashikant B. Mane, Madhav P.Kanse, Hema S. Mohite, Shila D. Kadam. STUDY OF FRONTAL AIR SINUS OPENING IN HIATUS SEMILUNARIS OF NASAL CAVITY. Int J Anat Res 2018;6(1.1):48444848. DOI: $10.16965 /$ ijar.2017.481 